\title{
Worked shell from the Northern Moluccas
}

\author{
Katherine Szabó
}

\section{Introduction}

The Northern Moluccas occupy a pivotal geographical zone at the interface of the Island Southeast Asian and Melanesian spheres. Whether one looks at genes, languages, Holocene animal translocations, or the archaeological record, it is clear that the cultures through time on these islands have both been shaped by, and have contributed to shaping, the complex fusion of influences that characterises the Asia/Pacific margin. The project reported on in this monograph intensively investigated this area for the first time, and uncovered a rich range of sites spanning c. 35,000 years of the islands' history.

There are few constants in the archaeological record that can be tracked through time. The vertebrate record of the Northern Moluccas shows dramatic shifts at different points in the past, and the ceramic record is necessarily restricted to the last few thousand years. The pre-eminence of lithic technology in the study of human cultural change through time is due to its global presence as a robust archaeological constant, but in Island Southeast Asia, and the Northern Moluccas in particular, another constant has emerged: shell technology.

From the earliest archaeological deposits at the oldest excavated site, Golo Cave, a range of shell technologies were in use ranging from the formal to the expedient (Szabó et al. 2007; Szabó and Koppel 2015). In contrast, associated lithic technologies were found to be non-standardised and uncomplicated in their manufacture (Szabó et al. 2007). While, to some extent, the early diversification of shell technologies at Golo Cave can be seen as a response to the low-quality lithic materials that were locally available, this in itself does not provide an adequate explanation. The diversity of shell-working from the lowest levels at Golo, both in terms of materials used and reduction techniques employed, clearly implies that a broad tradition of shell-working was well established by the time the site was initially occupied. Additionally, the techniques applied to various types of shell diverge from those applied to lithic material, confirming that shell was no simple technological substitute for stone.

The range of stratified sites excavated as part of this archaeological project provides snapshots through time of the rise and decline of a variety of shell-working traditions. Some have clear links beyond the Northern Moluccas whilst others are seemingly idiosyncratic. The shell artefacts will be reported upon site by site, with temporal patterning and extra-Moluccan associations being considered in the discussion section. 


\section{Background and methods}

Worked shell was recovered from a range of sites excavated as part of this project. The largest sample comes from the longest sequence at Golo Cave. However, Uattamdi also yielded a range of artefacts from mid to late Holocene deposits. Smaller numbers were identified from Buwawansi, Siti Nafisah, and Tanjung Tulang. All artefacts are itemised along with their provenance details in Table 9.1.

The majority of the worked shell items reported on here were identified in the field individually as special finds and bagged according to provenance. It is thus possible that some minimally worked or unmodified-utilised shell was overlooked in this process. From the sample of shell artefacts available for study, the approach to the separation of potentially worked shell in the field seems to have been cautious, but the overall degree of potential bias in identification and retention is unclear. Only the Golo Cave sample also had associated shell midden samples that were readily available for study, and much of the Pleistocene worked shell identified came from the midden samples. Not all midden from the Golo Cave excavations was brought back to Australia, but a full sequence from Square M4, as well as additional samples collected for potential radiocarbon dating, was accessible.

Table 9.1 Worked shell identified from Northern Moluccan archaeological sites.

\begin{tabular}{|c|c|c|c|}
\hline Square & Depth (cm) & Species & Artefact type \\
\hline \multicolumn{4}{|c|}{ Golo Cave, Gebe } \\
\hline Surface & & Cassis cornuta & Reworked adze \\
\hline M9 & $0-5$ & Cassis cornuta & Adze \\
\hline M7 & $5-10$ & Turbo marmoratus & Cut fragment \\
\hline N6 & $5-10$ & Cassis cornuta & Adze \\
\hline N6 & $10-15$ & Cassis cornuta & Adze \\
\hline M7 & $10-20$ & Turbo marmoratus & Operculum artefact \\
\hline M4 & $15-20$ & Cassis cornuta & Adze fragment \\
\hline N6 & $15-20$ & Cassis cornuta & Adze \\
\hline M6 & $20-25$ & Cassis cornuta & Adze \\
\hline N6 & $25-30$ & Cassis cornuta & Adze \\
\hline LM6 & $25-30$ & Cassis cornuta & Adze \\
\hline M7 & $35-40$ & Cassis cornuta & Adze \\
\hline M5 & $40-45$ & Cassis cornuta & Adze fragment \\
\hline M5 & $40-45$ & Conus sp. & Modified spire \\
\hline M5 & $40-45$ & Conus sp. & Modified spire \\
\hline M6 & $50-55$ & Cassis cornuta & Adze \\
\hline M5 & $50-55$ & Cassis cornuta & Worked lip fragment \\
\hline L6 & 55 & Cassis cornuta & Adze \\
\hline M8 & $55-60$ & Turbo marmoratus & Worked fragment \\
\hline M6 & $60-65$ & Cassis cornuta & Adze fragment \\
\hline M5 & $75-80$ & Turbo marmoratus & Cut fragment \\
\hline N6 & 100 & Hippopus hippopus & Rib-portion adze \\
\hline M6 & 100 & Tridacna sp. & Rib-portion adze \\
\hline M5 & $100-110$ & Turbo marmoratus & Operculum artefact \\
\hline LM6 & $125-130$ & Tridacna sp. & Rib-portion adze \\
\hline M4 & $135-140$ & Tridacna gigas & Rib-portion adze \\
\hline LM6 & $145-150$ & Hippopus hippopus & Rib-portion adze \\
\hline M4 & $170-180$ & Turbo marmoratus & Operculum artefact \\
\hline
\end{tabular}




\begin{tabular}{|c|c|c|c|}
\hline Square & Depth (cm) & Species & Artefact type \\
\hline M4 & $180-185$ & Pinctada margaritifera & Cut fragment \\
\hline M4 & 185-190 & Scutellastra flexuosa & Utilised shell \\
\hline M4 & 190-200 & Turbo marmoratus & Operculum artefact \\
\hline LM6 & $195-200$ & Turbo marmoratus & Reduced shell \\
\hline M4 & 200-205 & Scutellastra flexuosa & Three utilised shells \\
\hline M4, LM6 & 200-210 & Turbo marmoratus & Four operculum artefacts \\
\hline M4 & $205-210$ & Scutellastra flexuosa & Utilised shell \\
\hline LM6 & $210-220$ & Turbo marmoratus & Reduced shell \\
\hline M5, LM6 & $210-220$ & Turbo marmoratus & Two operculum artefacts \\
\hline M5 & $220-230$ & Turbo marmoratus & Four operculum artefacts \\
\hline M5 & $230-240$ & Turbo marmoratus & Three operculum artefacts \\
\hline \multicolumn{4}{|c|}{ Uattamdi, Кауоа } \\
\hline $\mathrm{D} 1$ & Spoil & Cypraea tigris & Perforated dorsum \\
\hline C7 & B6 & Isognomon isognomum & Worked and utilised valve \\
\hline D4 & $\mathrm{C} 2$ & Isognomon isognomum & Shaped valve \\
\hline C6 & C3 & Pinctada maxima & Worked and utilised valve \\
\hline 05 & C3 & Asaphis violascens & Shaped fragment \\
\hline D4 & $\mathrm{C3}$ & \begin{tabular}{|l|} 
Nautilus sp. \\
\end{tabular} & Cut septal wall fragment \\
\hline D8 & C4 & Placuna ephippium & Cut fragment \\
\hline D9 & C5 & Conus sp. & Ring fragment \\
\hline C5 & $C 5$ & Trochus niloticus & Ring fragment \\
\hline $\mathrm{C} 5$ & C5 & Spondylus or Chama sp. & Ground bead \\
\hline C5 & C5 & Spondylus or Chama sp. & Ground bead \\
\hline D9 & C6 & Pinctada maxima & Worked and utilised valve \\
\hline D8 & C7-8 & Trochus niloticus & Ring fragment \\
\hline D8 & C7-8 & Trochus niloticus & Ring fragment \\
\hline $\mathrm{C7}$ & D3 & Cypraea tigris & Ground dorsum \\
\hline $\mathrm{C7}$ & D4 & Hippopus hippopus & Shaped fragment \\
\hline \multicolumn{4}{|c|}{ Buwawansi, Gebe } \\
\hline B1 Square B & $35-40$ & Tridacna gigas & Rib-portion adze \\
\hline $\mathrm{B} 4 / 5$ & Surface find & Conus sp. & Complete ring \\
\hline \multicolumn{4}{|c|}{ Tanjung Tulang, Morotai } \\
\hline N5 & $15-20$ & Placuna placenta & Shaped valve \\
\hline N5 & $15-20$ & Melo sp. & Utilised lip \\
\hline \multicolumn{4}{|c|}{ Siti Nasifah, Halmahera } \\
\hline F5 & A1 & Nautilus sp. & Cut body fragment \\
\hline
\end{tabular}

Source: Katherine Szabó.

For sites other than Golo Cave, shell pieces identified as worked were either formal and highly modified artefacts or fragments of known raw materials (e.g. Turbo marmoratus, Pinctada spp.) with possible evidence of cutting or shaping. Both categories were studied with the aid of a Dino-Lite Premier AD7013MT portable digital microscope to assess finer details of clearly or potentially worked surfaces. The confirmation of a fragment as 'worked' required distinct evidence of tool use, human-mediated fracture or use-wear traces not able to be replicated by the action of taphonomic processes. Human-mediated fracture also potentially took in any shells that were deliberately broken to extract the flesh for consumption, and a discussion of such shells is presented below within the Uattamdi results. 
Given that shell midden was available for study for Golo Cave, the analytical procedures followed were different from the other assemblages. Shell from Pleistocene archaeological assemblages is frequently minimally worked, and thus presents obstacles for the identification, analysis, and interpretation of any shell artefacts. An extended discussion of these issues has been presented in Szabó (2013). All shell available from the Golo Cave excavations was studied, and unusually shaped pieces as well as fragments from known major raw materials (e.g. Tridacna spp.) were separated for further analysis. In order to assess accurately the presence and nature of shellworking, technological studies (e.g. Szabó et al. 2007), and extensive experimental programs (e.g. Szabó and Koppel 2015) were undertaken, and aspects of these are ongoing.

\section{Results of analysis}

\section{Golo Cave}

Aspects of the worked shell from Golo Cave have already been the subject of a number of specialist papers (Szabó et al. 2007; Szabó 2013; Szabó and Koppel 2015), which have begun to reveal the extent and nature of early shell-working at the site. This published work will not be reiterated in detail here, but summaries of the findings are given along with additional discussion of other shell artefacts present in the Golo samples and a précis of ongoing research.

During the course of sorting the midden shell, a number of flakes and seemingly shaped pieces of Turbo marmoratus operculum were identified. Further investigation confirmed that the large (c. $500 \mathrm{gm}$ in weight) opercula had been deliberately shaped through the removal of sequential flakes from the perimeter using direct percussion (Figs 9.1(a) and 9.1(b)) (Szabó et al. 2007). Some of the resulting flakes also showed signs of retouch (Fig. 9.1(c)). Initially, it was hypothesised that this distinctive knapped shell technology represented a technological transfer from lithic materials in the absence of good stone resources. However, detailed study revealed that the T. marmoratus operculum knapping techniques were more complicated and structured than those seen in associated lithic artefacts at Golo Cave. This, coupled with an associated diversity in shell-working technologies in the lowermost levels of the site, confirmed that shell technologies were separate from those seen in stone and that they must have had an ancestry reaching before the initial occupation of Golo Cave.

Also, whilst sorting the midden, a small number of specimens of the common limpet species gathered for consumption (Scutellastra flexuosa) were separated for further investigation due to visible rounding of part of the shell margin. This species has a sharp, crenelated margin, and taphonomic assessments as well as experimental fracture tests demonstrated that the damage noted on the shells could not have occurred through these mechanisms (Szabó and Koppel 2015). After an experimental program, which established baseline usewear traces for a variety of material textures, five $S$. flexuosa shells were identified as showing clear modification as a result of sustained human use. As with the T. marmoratus operculum artefacts, all of these shells derived from the lowermost Golo Cave deposits. Two shells displayed edge-faceting that indicated they had been used to scrape a hard material, with a further shell having edge rounding consistent with experimental specimens generated through the scraping of fresh bone (Figs 9.2(a) and 9.2(b)). The remaining two specimens had discrete patches of attritional wear on their dorsal surfacesparticularly on the elevated radial ribs. Experimental specimens used to scoop coconut flesh from the shell showed similar wear, but the restriction of abrasion to the elevated rib surfaces with little alteration to the intervening furrows indicates that the material being worked was less malleable than coconut flesh. Full details of all experiments and results are reported in Szabó and Koppel (2015). 


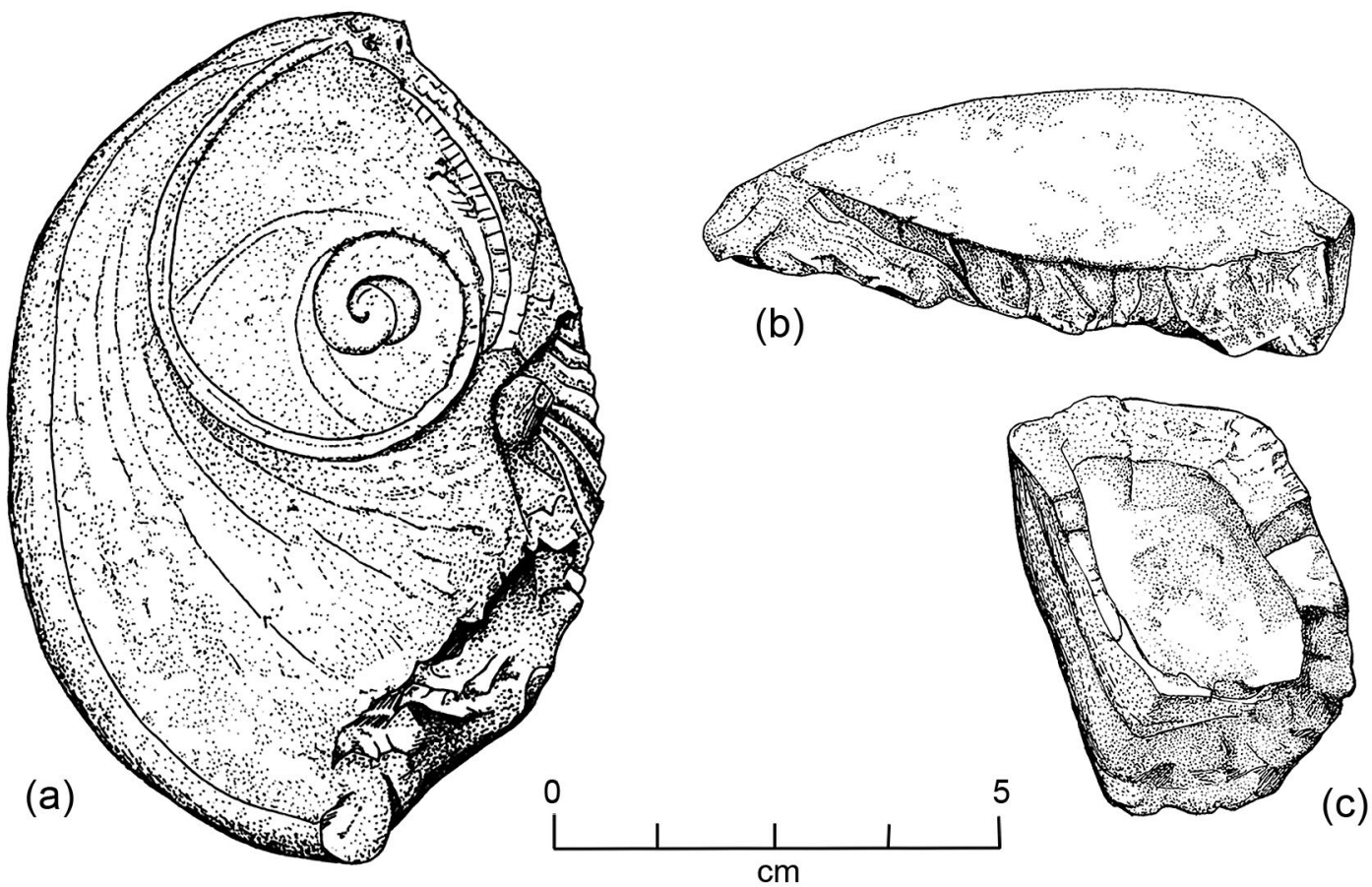

Figure 9.1 Worked Turbo marmoratus operculum fragments from Golo Cave.

(a) operculum shaped by sequential flaking of the perimeter, Square L6-M6 200-205 cm; (b) bending-initiated operculum flake, Square M5 230-235 cm; (c) retouched fragment of operculum, Square L6-M6 200-205 cm.

Source: Katherine Szabó, drawings by Fernando Lero.
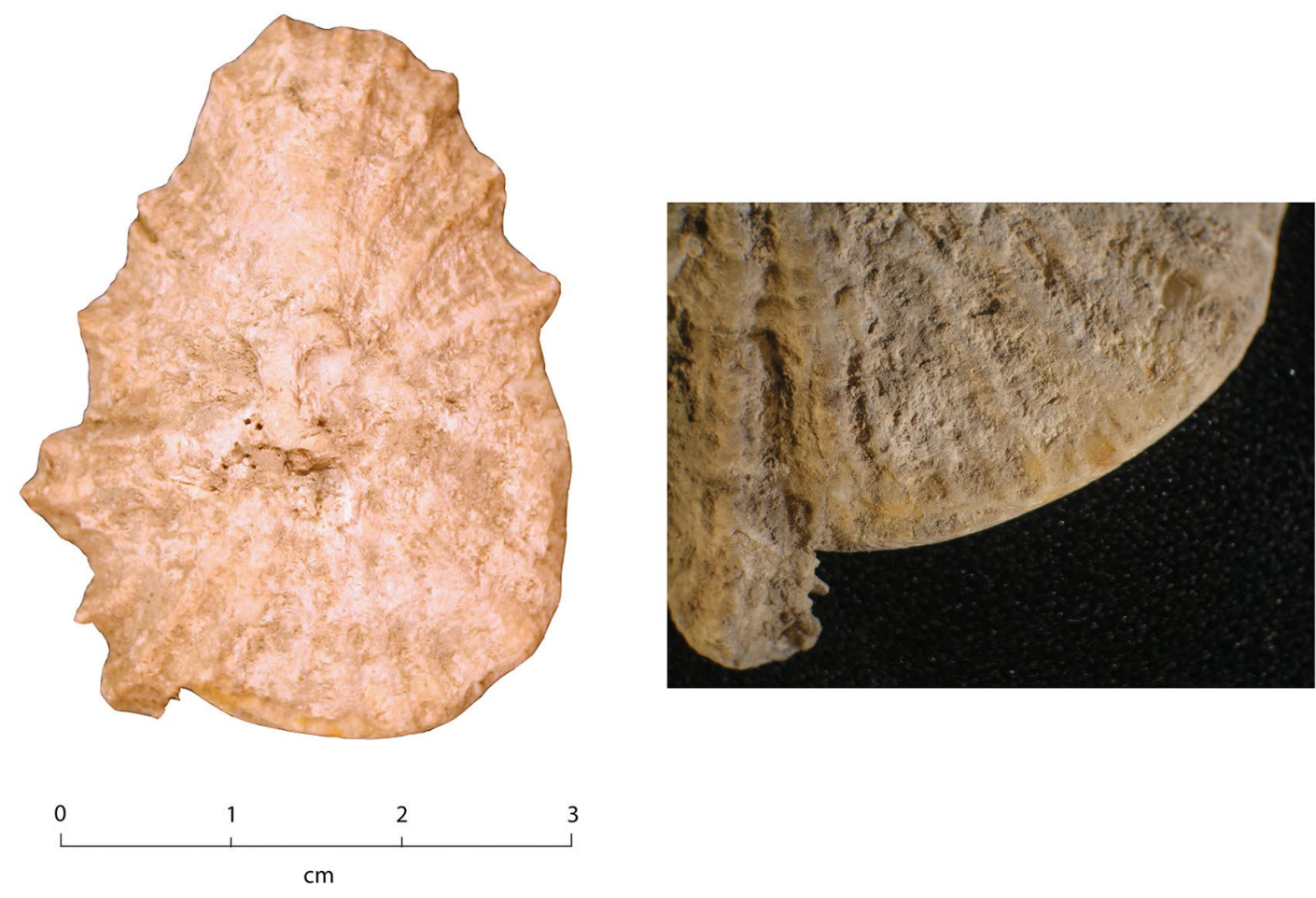

Figure 9.2 Scutellastra flexuosa modified tool from Golo Cave.

(a) limpet modified through use, Square $M 4200-205 \mathrm{~cm}$; (b) modified portion of the same specimen at $25 \mathrm{x}$ magnification. Source: Katherine Szabó. 
In addition to the expedient $S$. flexuosa tools and the knapped T. marmoratus operculum artefacts, a further worked shell was identified from below $190 \mathrm{~cm}$ at Golo Cave. A reduced Turbo marmoratus shell was recovered from LM6 at $210-220 \mathrm{~cm}$ depth, with another excavated from $195-200 \mathrm{~cm}$ in the same unit. Both shells have had a hole knocked through the penultimate whorl on the ventral surface, but the 195-200 $\mathrm{cm}$ deep example also has extensive reduction of the shell from the aperture back into the body whorl, as well as at the apex and upper whorls (Figs 9.3(a) and 9.3(b)). While the hole in the centre of the shell seems to have been generated through freehand percussion on both specimens, the further reduction seen in the 195-200 cm example has been affected through chipping with a sharp point. The notches from this activity can be seen in Figure 9.3(b).

Between a depth of $100 \mathrm{~cm}$ and $140 \mathrm{~cm}$ in Golo Cave, five giant clam adzes were recovered during the excavations (Table 2.2 and Fig. 9.4). Three are discussed here, ${ }^{1}$ and another large Tridacna specimen is illustrated in Figure 8.7 in the previous chapter. Two of the specimens discussed here are manufactured from species of Tridacna, and one from Hippopus hippopus. All are made from a single rib of a valve, meaning that the cutting edge is slightly convex in profile, mirroring the shape of the shell margin. The choice of this portion of the shell for adze production is typical of preceramic sites in the eastern Indonesia and New Guinea regions (Szabó 2005). Only the poll end is present from the lowermost example recovered from 125-130 cm (Fig. 9.4(c)), but the bevels and cutting edges of both of the other specimens have many striations running perpendicular to the cutting edge (Figs 9.4(b) and 9.4(e)). The poll ends of these specimens also have extensive abrasion and polish on the most elevated portions. The morphology of the polished surfaces indicates that this wear was acquired through the rubbing of hafting apparatus rather than deliberate modification.
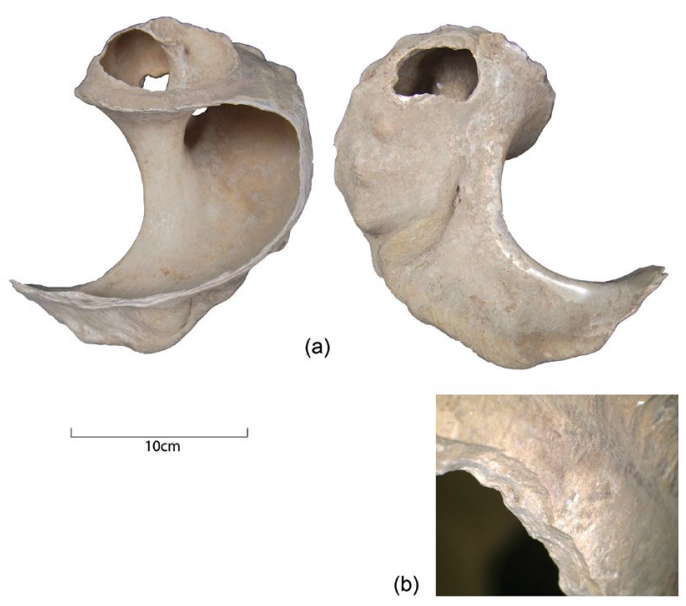

Figure 9.3 Reduced Turbo marmoratus shell from Golo Cave, Squares L6-M6 195-200 cm.

Inset shows the chipping near the apex at 10x magnification.

Source: Katherine Szabó.

From a depth of $65 \mathrm{~cm}$ upwards to the surface, 10 complete, four partial and one reworked Cassis cornuta adzes were recovered in Golo Cave (Fig. 9.5). This is a remarkable assemblage that is unparalleled elsewhere in Southeast Asia, with C. cornuta being a raw material more traditionally associated with the Pacific Islands. A number were also found in the upper deposits of Wetef Cave (see Chapter 8). All of the adzes are manufactured from the robust, thickened lip of the shell, with patches of grinding restricted to the bevel and sometimes parts of the lateral edges. The bevels of most specimens seem to have been ground using a cylindrical or convex grinding stone, meaning that the bevels are mostly convex in profile. The bevels are ground from the interior surface of the adze, with a minimum of smoothing on the outer/dorsal surface.

1 One Tridacna and one Hippopus shell adze from Golo were used in an artefact display in the School of Archaeology and Anthropology at ANU, and were inadvertently omitted from the assemblage sent to Katherine Szabó at the University of Wollongong. They are not described in this chapter, but the Tridacna specimen is shown in Figure 8.7 (previous chapter). 


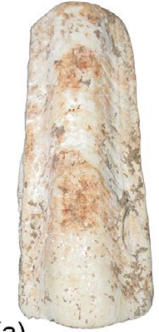

(a)
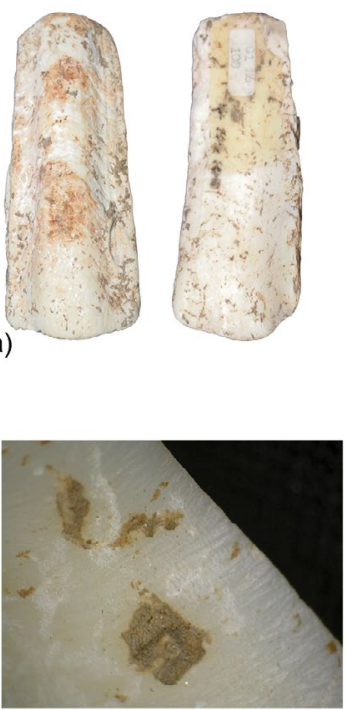

(e)

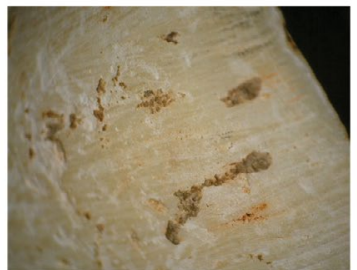

(b)

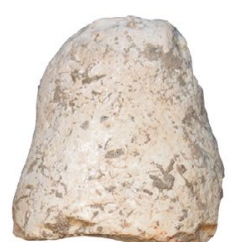

(c)

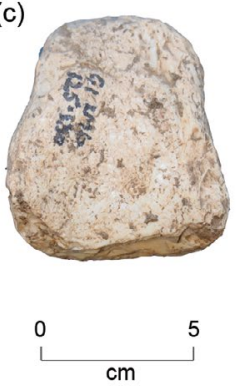

Figure 9.4 Giant clam adzes from Golo Cave.

(a) Hippopus hippopus adze, Square N6 $100 \mathrm{~cm}$; (b) usewear striations perpendicular to the cutting edge, H. hippopus adze, Square N6 100 cm, 40x magnification; (c) broken Tridacna sp. adze, Squares LM6 125-130 cm; (d) Tridacna sp. adze, Square M6 100 cm; (e) usewear striations perpendicular to the cutting edge, Tridacna sp. adze, Square M6 $100 \mathrm{~cm}$, 40x magnification. Source: Katherine Szabó.

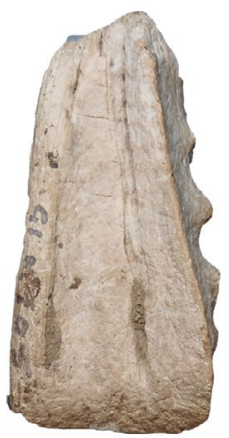

(a)

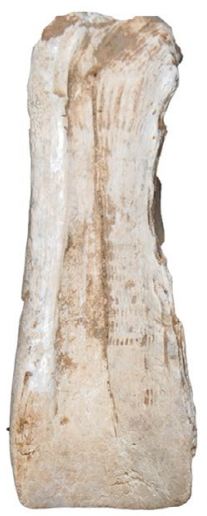

(c)

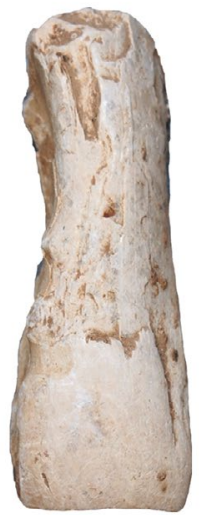

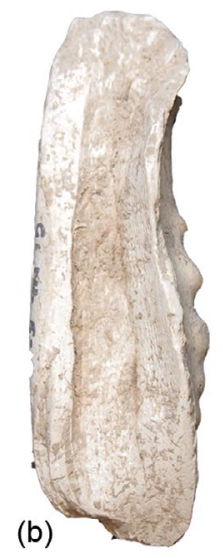

0

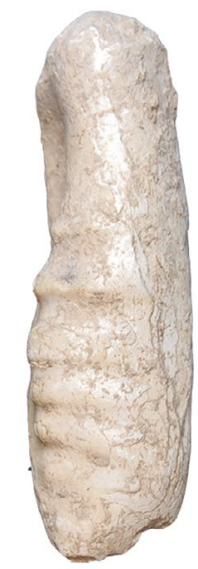

5

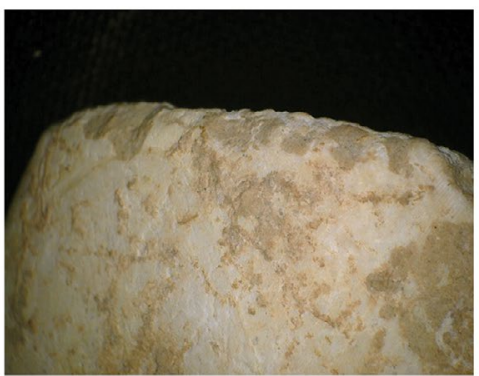

Figure 9.5 Cassis cornuta adzes from Golo Cave.

(a) curated adze, Square M9 0-5 cm; (b) adze, Square M6 20-25 cm; (c) adze, Square M6 50-55 cm; (d) impact flakes on bevel of a curated adze, Squares LM6 25-30 cm, 10x magnification.

Source: Katherine Szabó. 
During analysis it was noted that two distinct types of $C$. cornuta adzes were present in the assemblage: a larger original form (Figs 9.5(b) and 9.5(c)) and a smaller, curated form with more variable morphology (Fig. 9.5(a)). The curated form sometimes has the bevel ground on a flat grinding slab rather than the convex grindstone detailed above. In total, five of the complete adzes from Golo are curated examples and five are non-curated. The non-curated examples, however, also have clear evidence of usewear at the cutting edge and often the poll, so they are certainly finished and used tools. The curated examples likewise show evidence of use (Fig. 9.5(d)).

Direct AMS radiocarbon dating of a C. cornuta adze recovered from Square M5, 30-35 cm, returned an Early Holocene date (OZD773, 9580 70 uncal. BP), which is clearly at odds with its stratigraphic position. Although none of the adzes were made of fossilised shell, as was the case with the preceramic adzes at Duyong Cave in the Philippines (Szabó 2005), it seems likely that subfossil shell was selected for their production. Thus, direct radiocarbon dating will produce spurious archaeological results, as discussed already in Chapter 8.

Two modified Conus sp. spires were identified during excavation-both from Square M5 at a depth of $40-45 \mathrm{~cm}$. Both spires show clear evidence of rounding and attrition through the action of coastal taphonomic processes (Zuschin et al. 2003), meaning that both artefacts were collected post-mortem from the strandline as already abraded spires. Despite this, both artefacts show evidence of further modification after initial collection. The first Conus sp. spire (Fig. 9.6(a)) is smooth and water-rolled on both the interior and exterior surfaces. However, the apical area has been further smoothed through manual freehand abrasion. The perforation, which could be naturally formed, has been regularised through either deliberate modification or use (Fig. 9.6(b)). The second Conus sp. spire (Fig. 9.6(c)) differs from the first in its condition; it has been heavily burnt, which has recrystallised the shell into a blocky texture. Despite this, the apical area also shows additional smoothing (Fig. 9.6(d)).

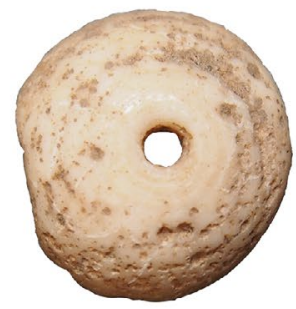

(a)

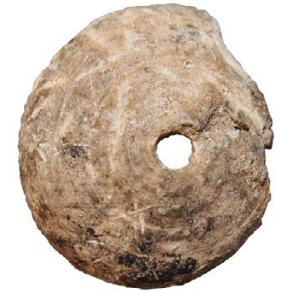

(c)

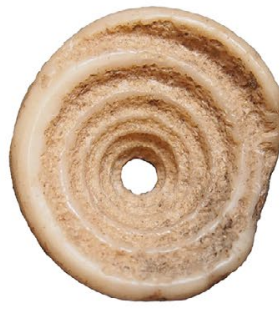

(b)
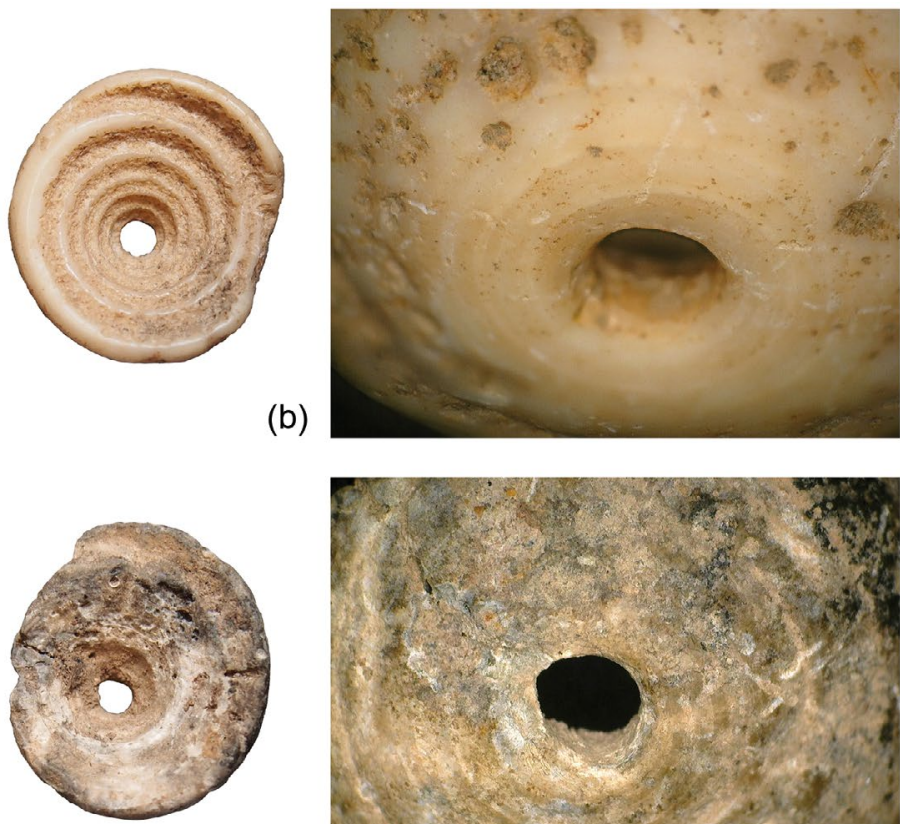

(d)

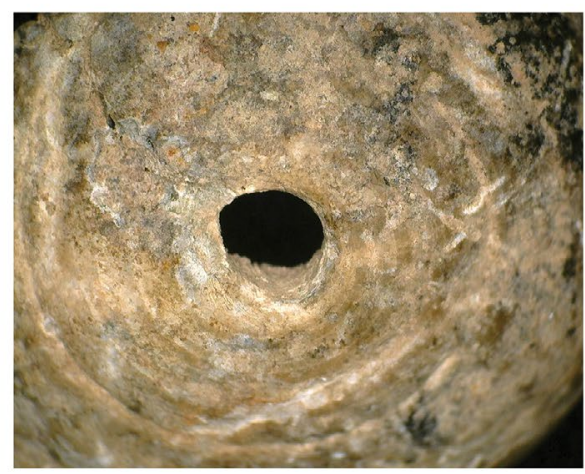

Figure 9.6 Modified Conus sp. spires from Golo Cave, Square M5 40-45 cm.

(a) complete modified spire; (b) detail of perforation of complete spire, 30x magnification; (c) burnt modified spire; (d) detail of perforation of burnt spire, 25x magnification.

Source: Katherine Szabó. 
The remaining pieces of worked shell from Golo Cave are a series of cut and/or shaped fragments from Turbo marmoratus, Nautilus sp. and Pinctada margaritifera shell. At present, experimental reduction is being undertaken with all of these taxa to categorically demonstrate the nature of working. Nautilus spp. in particular is a material that is dissimilar to other types of shell in that it is comprised of some microstructural types rare in other types of shell (Watabe 1988). Additionally, the shell is mechanically adapted to a range of forces different to that experienced by inshore species. Being pelagic and descending to considerable depths, water pressure is a significant force that Nautilus spp. shell is specifically adapted to withstand (Currey 1988:198). None of the fragments of T. marmoratus, P. margaritifera, or Nautilus sp. have enough in the way of shaping to indicate a final form or function. Nevertheless, the presence of cutting as a shellworking technique within both the Pleistocene and Holocene levels of Golo Cave is significant in itself (Szabó 2013).

(a)
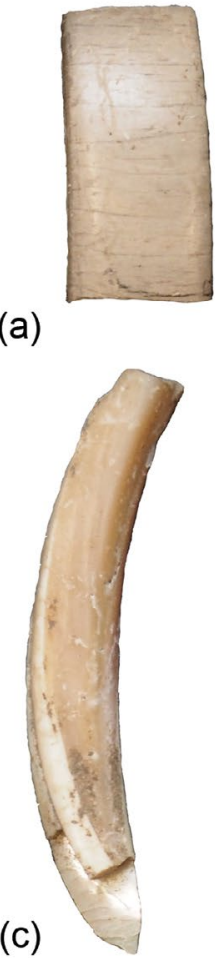
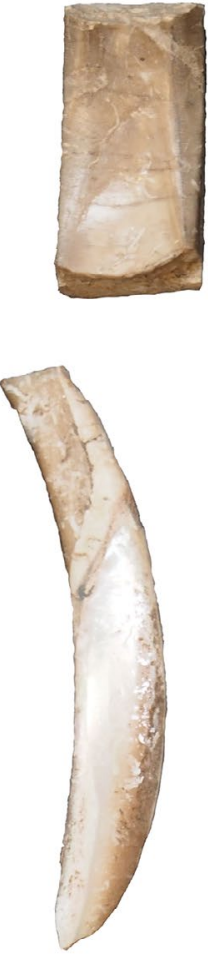

(b)
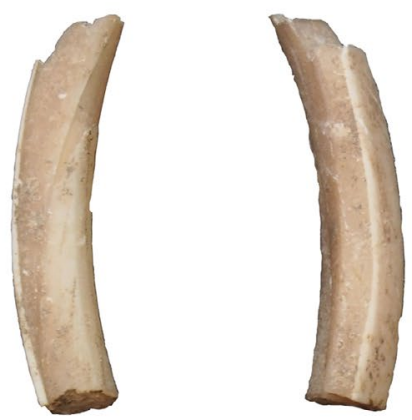

(d)
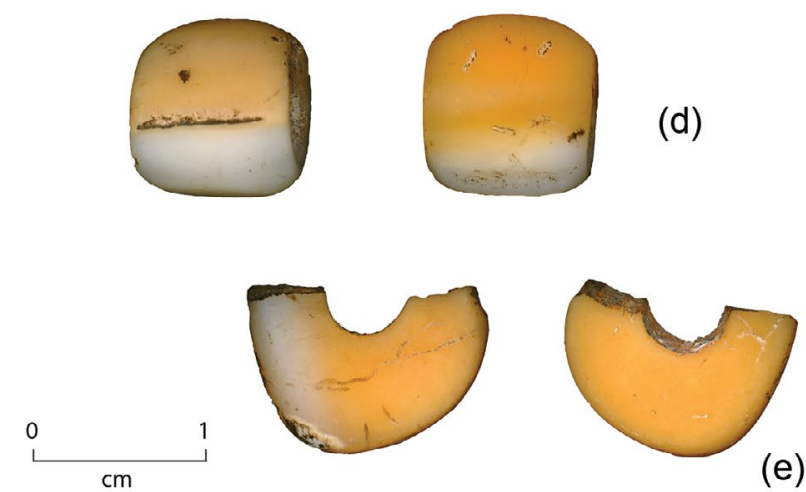

Figure 9.7 Formal shell artefacts from Uattamdi 1.

(a) Conus sp. ring fragment, Square D9 Layer C5; (b) and (c) Trochus niloticus ring fragments from different rings, Square C8 Layer C7-C8; (d) barrel bead made of Spondylus sp. or Chama Sp., Square C5 Layer C5; (e) broken disc bead made of Spondylus sp. or Chama sp., Square C5 Layer C5.

Source: Katherine Szabó.

\section{Uattamdi 1}

Sixteen shell artefacts were identified during the Uattamdi 1 excavations, including both formal and expedient artefact types. All the artefacts bar one, a shaped and utilised valve of the mangrove pearl oyster Isognomon isognomum, derive from the lower Neolithic layer rather than the overlying Early Metal phase deposits. The overall assemblage comprises a mix of formal artefact types and expedient tools. The formal artefacts will be covered first.

Three fragments of Trochus niloticus ring, two fragments from Square D8 Layer C7-C8 (Figs 9.7(b) and 9.7(c)) and one from Square C5 Layer C5, were identified during excavation. Measurements indicate that they probably derive from different rings. All three are well-ground and clearly 
finished and used artefacts. A further ring fragment made from Conus sp. shell was excavated from Square D9 Layer C5 (Fig. 9.7(a)), and is also well polished and worn. Two unusual beads were also recovered from Uattamdi Layer C. They are both manufactured in the same material, with the orange-and-white mottling and surface texture suggesting that either a species of Spondylus or Chama was the raw material used. One is a squat barrel bead, fully ground and drilled end to end (Fig. 9.7(d)), and the other is half of a disc bead that is rather wedge-shaped in profile with nonparallel faces (Fig. 9.7(e)). Both are also shown in Figure 8.8. These beads have no analogues at the other Northern Moluccan sites or indeed elsewhere in Southeast Asia.

A series of dorsa from the large cowrie Cypraea tigris was collected from Uattamdi. In the Pacific, these are frequently-and controversially-described as 'octopus lures' based on Polynesian ethnographic examples. Archaeological specimens, however, rarely show signs of the modifications seen in the ethnohistorical artefacts, such as perforations through which to lash the cowrie dorsa to the central cane around which they are fastened. Spennemann (1993) investigated patterns of cowrie breakage in natural coastal settings and found that many modified cowries assumed to be tools could be regarded as the results of natural breakage patterns. Cowries are also collected for consumption, and given the narrow morphology of the aperture, breakage to extract the meat is common (Spennemann 1993). Experimental work undertaken as a part of my doctoral thesis (Szabó 2005) showed that it was easy to remove the dorsum of a large Cypraea shell with a single blow with a hammerstone to the anterior or posterior of the shell. Spennemann, recording breakage for meat extraction in Tonga, notes that in recent times an iron rod is driven through the shell and then the hole widened to extract the animal (Spennemann 1993:46). All but two examples of Cypraea tigris dorsa recovered from Uattamdi show no grinding, abrasion, or deliberate perforation. Indeed, most specimens show a rough notch at either the anterior or posterior end, surrounded by a zone of crushing, which indicates the dorsa were removed through the application of a single blow (Fig. 9.8(f)).

Of the two examples that show definite signs of modification beyond meat extraction, one was found in the spoil from the excavation of Square D1. Two small, parallel pierced perforations are positioned at one end of the dorsum, but given the lack of context little of interpretive value can be stated. The second is one of the deepest pieces of worked shell recovered from excavations at Uattamdi, and one of only two from Layer D (Square C7 Layer D3). A C. tigris dorsum, polished through handling, has been ground around the perimeter of the break surface (Fig. 9.8(a)). The angles and regularity indicate that it was ground on a flat grinding slab, although subsequent handling wear has muted and rounded the corners (Fig. 9.8(b)). There are no perforations or indications of lashing, nor do any of the edges show usewear associated with a scraping or peeling function, so its function remains unknown.

As with large cowrie shells, Pinctada spp. pearl oyster valves are sometimes classified as scrapers or peelers based, most commonly, on ethnographic analogy and sometimes confirmed through observations of usewear. At Uattamdi, two valves of the Golden-lipped Pearl Oyster, Pinctada maxima, as well as two valves of the Mangrove Pearl Oyster, Isognomon isognomum, have distinct modifications resulting from extended use as expedient tools. The two $P$. maxima shells are nearcomplete valves (Fig. 9.8(d)), with usewear striations along one or more zones of the margin (Fig. 9.8(e)) and deliberate abrasion at the hinge area to remove rough surfaces when the valve is gripped. The striations run parallel to the margin, indicating a cutting rather than scraping function. I. isognomum valves are less robust than P. maxima shells, but one near-complete valve (Square C7 Layer B6) has similar modifications to those seen in P. maxima, while the other worked I. isognomum shell (Square D4 Layer C2) has had the hinge end deliberately removed with the margins being shaped to create a spoon-like morphology. On all four valves the outer, dull prismatic exterior layer of shell has been purposefully removed, leaving only the mother of pearl layers. 


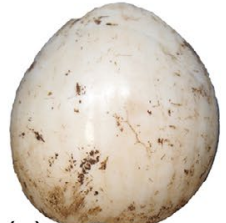

(a)

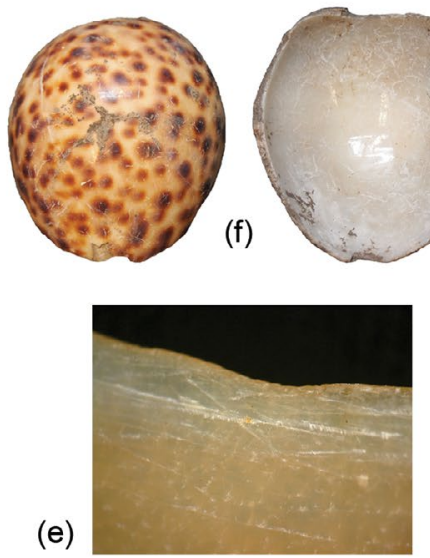

(b)

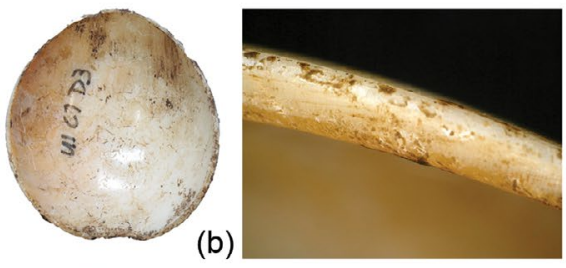$$
5 \mathrm{~cm}
$$
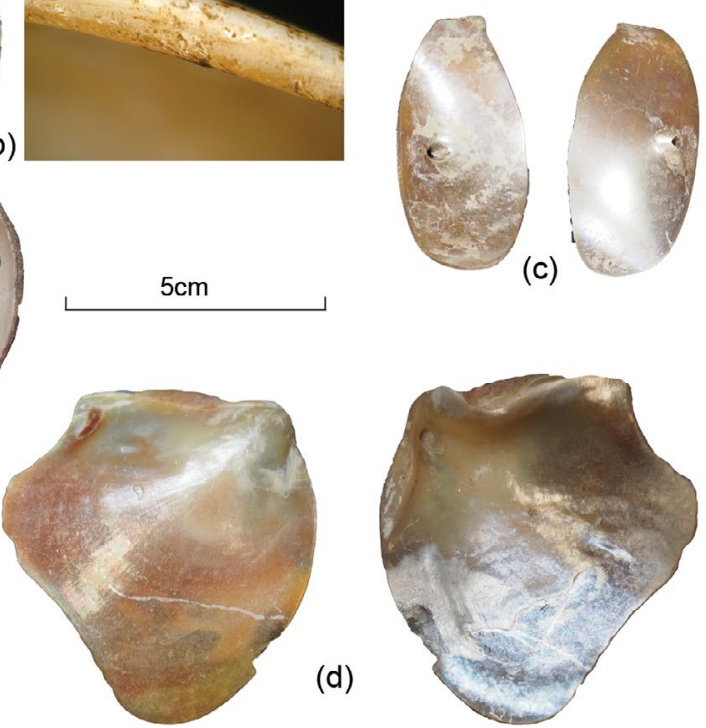

(d)

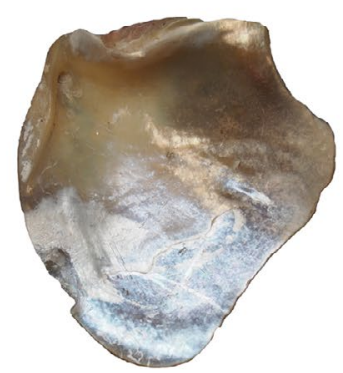

Figure 9.8 Informal and expedient artefacts from Uattamdi 1.

(a) ground Cypraea tigris dorsum, Square C7 Layer D3; (b) detail of grinding on C. tigris dorsum, 40x magnification; (c) shaped Nautilus sp. septal wall fragment, Square D4 Layer C3; (d) Pinctada maxima knife, Square D9 Layer C6; (e) detail of striations parallel to edge on $P$. margaritifera knife, 30x magnification; (f) unworked C. tigris dorsum showing evidence of breakage for meat extraction, Square D8 Layer $C 5$.

Source: Katherine Szabó.

Also in mother of pearl, but manufactured from Nautilus sp. shell, is a cut, oval fragment (Fig. 9.8(c)). It has been made from one of the inner septal (chamber) walls, with the perforation being the natural hole created by the animal to accommodate the siphuncal tube through which it regulates buoyancy. The edges of the siphuncal hole are still sharp, indicating that this artefact has seen little or no use.

A small selection of shells from other species have minor evidence of working, including a cut piece of the thin oyster relative Placuna ephippium, a hinge fragment of a Hippopus hippopus valve showing some signs of direct percussion, and a margin fragment of the common bivalve Asaphis violascens with deliberate knapping along the margin. Provenance details for these artefacts are given in Table 9.1.

\section{Buwawansi}

Two shell artefacts were recovered from Buwawansi. A large Tridacna gigas adze (Fig. 9.9(a)) is very thick and robust with a very curved cutting edge. It has been manufactured from a single rib from the thickest portion of the shell close to the hinge. The bevel area is most intensively abraded - through both deliberate modification and use-with other portions of the adze showing less attrition. The area around the poll shows high polish and abrasion of the surfaces in highest relief (Fig. 9.9(b)), and this wear pattern is most probably associated with hafting. The pit-marks on the outer surface derive from the action of marine bioeroders, including Cliona spp. sponges and Lithophaga boring mussels, on the original raw material rather than being caused by post-depositional processes.

The second artefact is a complete Conus sp. ring (Fig. 9.9(c)). Although it appears unfinished, with much of the second whorl still present along the interior surface, edge-rounding indicates that it has been worn extensively. 


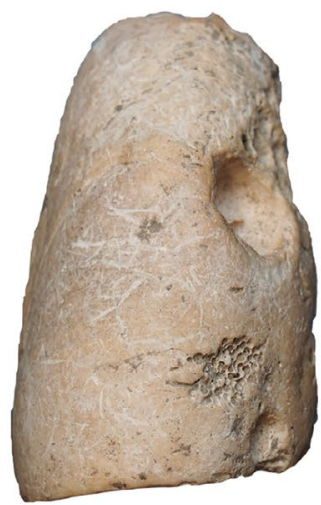

(a)
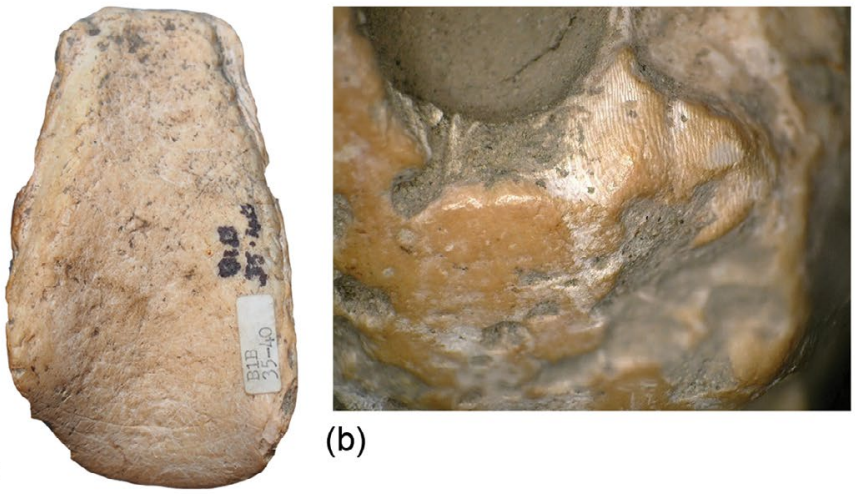

(b)

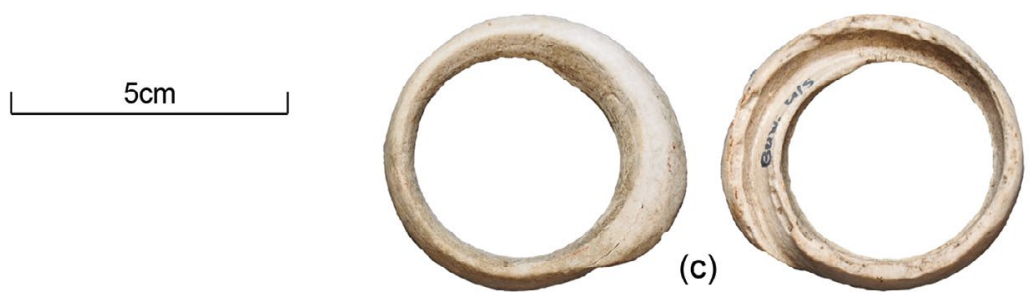

Figure 9.9 Shell artefacts from Buwawansi.

(a) Tridacna gigas adze, Square B 35-40 cm; (b) detail of polish and abrasion at poll end of adze, 30x magnification;

(c) Conus sp. ring, surface find.

Source: Katherine Szabó.

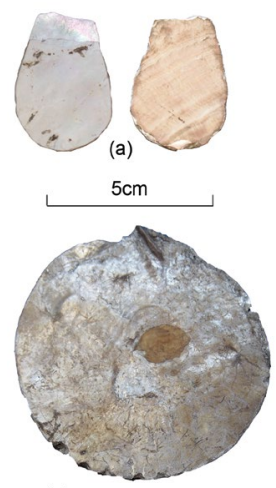

(e)

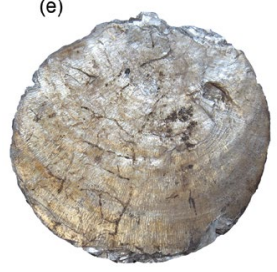

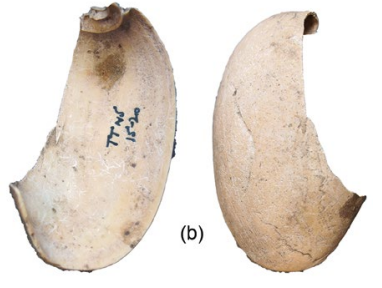

(c)

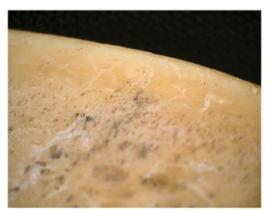

(d)

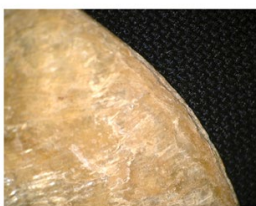

Figure 9.10 Worked shell from Gua Siti Nafisah and Tanjung Tulang.

(a) cut Nautilus sp. fragment, Gua Siti Nafisah Square F5 Layer A1; (b) Melo sp. scraper/peeler, Tanjung Tulang Square N5 15-20 cm; (c) detail of rounding at lip of Melo sp. scraper/peeler, $25 \mathrm{x}$ magnification; (d) detail of trimmed edge of Placuna placenta disc, 20x magnification; (e) Placuna placenta trimmed disc, Tanjung Tulang Square N5 15-20 cm on bedrock.

Source: Katherine Szabó.

\section{Gua Siti Nafisah}

A single piece of worked shell was identified from Gua Siti Nafisah. A teardrop-shaped cut fragment of Nautilus sp. was identified from the uppermost deposits in Square F5 (Fig. 9.10(a)). It is cut from the body of the shell, and the outer cream-coloured shell layer is still present. Beyond the cutting there is no further evidence of modification, either through working or use.

\section{Tanjung Tulang}

Only two pieces of worked shell were recovered from the Tanjung Tulang deposits. Both came from a depth of $15-20 \mathrm{~cm}$ in Square N5. The first is a section of body whorl from a small Melo sp. shell that retains the lip (Fig. 9.10(b)). A closer look at the central portion of the lip reveals edge-rounding and polish, with this attrition extending a couple inward into the body whorl (Fig. 9.10(c)). Although no striations are visible, this broad section of rounding and shell removal fits better with an explanation of use as a scraper or peeler than as a knife. 
The second is a solid disc shaped from a complete Placuna placenta valve (Fig. 9.10(e)). The edges of $P$. placenta valves are highly lamellar, thin, and fragile in their natural state, and the edges of this valve have been deliberately trimmed so that the edge is both regular and more robust (Fig. 9.10(d)). There are no further indications of modification or use.

\section{Discussion}

One of the most notable aspects of the worked shell assemblages from the various Moluccan sites is the diversity in raw materials used. Many of the commonly encountered molluscan raw materials of the Island Asia-Pacific region are present, including giant clams, Trochus niloticus, Turbo marmoratus, Nautilus sp., and Conus sp., but less widespread raw materials (e.g. Cassis cornuta, Isognomon isognomum) appear to have had a clear role in local shell-working traditions as well. Some of these lesser-seen raw materials were used in specific locations elsewhere in the Island Asia-Pacific region, as discussed further below. The relatively large number of expedient or minimally modified artefacts expands the roster of raw materials even further.

The expedient use of shell for undertaking everyday tasks is sometimes perceived to be haphazard in the selection of raw material, simply taking a convenient shell from associated midden deposits. But the general patterning in expedient tool materials in the Northern Moluccan assemblages would seem to argue otherwise. In the earliest deposits at Golo Cave, Scutellastra flexuosa shells were repeatedly recycled for use from midden deposits (Szabó and Koppel 2015). The recurrent use of pearl oysters - both Pinctada and Isognomon — at Uattamdi is also suggestive. Both genera were only minimally modified, with the outer, dull prismatic layer being removed and sections of the margin being trimmed where necessary to enhance functionality. It would certainly be interesting to assess the relationship between expedient shell tool raw material choice with bigger samples of worked shell, as well as associated midden shell, to build up a picture of available resources.

There is minimal evidence for the production of formal shell artefacts at either Golo Cave or Uattamdi, with no débitage associated with the production of either giant clam or Cassis cornuta adzes, or Trochus niloticus or Conus sp. rings. This, however, does not mean that the production of these artefacts was not local-perhaps it was just taking place elsewhere on the nearby landscape. The standardised patterns in curation noted for the C. cornuta adzes at Golo Cave show that there were clear formalised traditions of artefact (re)working.

There are no molluscan raw materials that are present at all of the sites from which shell artefacts were recovered. The most ubiquitous raw material, being present at Golo Cave, Uattamdi and Gua Siti Natisaf, is Nautilus sp. This taxon also has the greatest longevity as a raw material based on the current evidence. As discussed above, we understand little about the finer features of Nautilus spp. shell as a raw material and, due to this, worked examples across the region are likely under-reported. Preceramic Nautilus spp. working has been recorded for Timor Leste (Glover 1986; O'Connor 2010) and Flores (van den Bergh et al. 2009) in Island Southeast Asia, and in sites on the islands of Buka and Manus in Papua New Guinea (Szabó 2005). Timor is currently the only location from which finished artefacts have been recovered and at all other locations the end points of working are currently unclear.

Aside from the intermittent appearance of worked Nautilus sp. shell at three sites, there was little perceptible persistence of Moluccan shell-working traditions through time. The use of Turbo marmoratus was virtually restricted to the Pleistocene, and giant clam use a feature of the Holocene. The use of Cassis cornuta, based on stratigraphic positioning, was focused upon the last few thousand years, and the current evidence of Trochus niloticus and Conus spp. use 
suggests a similar time depth. There is certainly no evidence at present for a preceramic lineage of local shell-working for Conus sp. and T. niloticus. These temporal horizons in approaches to shell-working and raw material selection suggest that innovations and influences were dynamic through time, and that the conservative traditions of shell-working in locations such as Timor were not a feature of the Northern Moluccan record.

As well as clear differences in shell-working traditions through time in the Northern Moluccas, there were also distinct spatial differences. Temporally, there is no analogue for Golo Cave in the Northern Moluccas outside of Gebe Island, so comparisons are difficult. The nearby Wetef rockshelter, with a similar sequence, did not have depositional conditions conducive to the preservation of worked shell before the Holocene. In the Holocene deposits at Wetef, however, C. cornuta lip adzes were also recovered. ${ }^{2}$

Conversely, Uattamdi on Kayoa Island has provided the only evidence from the Northern Moluccas of Trochus niloticus working; a taxon that is of central importance to shell-working across Island Southeast Asia and the western Pacific. It is also the only site in Island Southeast Asia to have yielded beads manufactured in Spondylus/Chama shell. Beads identified as having been produced in Spondylus sp. shell have been identified for some Early Lapita deposits (Kirch 1988), and this shell was also widely used in Micronesia at a rather later date (e.g. Weisler 2000).

Current evidence thus suggests that there is much diversity between the shell-working traditions of different islands and areas within the Northern Moluccas, which in turn implies that their histories of cultural influence, innovation, and contact have been different. Indeed, given the number of islands it would be surprising if local histories and trajectories were not somewhat different. It may be significant that the $C$. cornuta adzes from Golo Cave and Wetef share much stylistically with $C$. cornuta adzes found in sites in Micronesia, Polynesia, and post-Lapita Melanesia. This putative link, however, does not seem to extend beyond Gebe Island to the rest of the Northern Moluccas, and this may matter when trying to reconstruct patterns of ancient contact and influence.

The worked shell samples from the Northern Moluccan excavations are not especially large, but they are diverse and instructive. It is clear that this region has had dynamic shell-working traditions stretching back to the earliest-known deposits. Indeed, the variety and skill in shell-working displayed within the earliest deposits at Golo Cave indicates that shell-working practices were already well-developed by this point. Waves of innovation are seen periodically, when new materials, artefact types, and ideas become manifest in a change in the material record. At the moment there are several large temporal gaps in our understanding of Northern Moluccan shell-working, and the spatial diversity seen in known shell-working traditions also suggests there is much to learn by focusing on, and comparing, individual islands. The Golo Cave assemblage has already transformed the way we think about, identify, and interpret Pleistocene shell-working in Island Southeast Asia. Further samples from this critical locale will undoubtedly add still more to our knowledge of cultural development at the interface of Southeast Asia and the Pacific.

\section{Acknowledgements}

Thanks to Brent Koppel, University of Wollongong, for his assistance in the photography and reanalysis of many of the Moluccan shell artefacts. Thanks also to Peter Bellwood for information about the assemblages and the opportunity to study them.

2 These C. cornuta adzes are currently restricted to Gebe Island and Flores (Galipaud et al. 2016) within the Island Southeast Asian archaeological record (Editor). 
This text is taken from The Spice Islands in Prehistory: Archaeology in the Northern Moluccas, Indonesia, edited by Peter Bellwood, published 2019 by ANU Press, The Australian National University, Canberra, Australia. 